\title{
Cultivation of Students' Multilingual Ability Against the Background of Internationalization Strategy of Colleges and Universities
}

\author{
Yan Teng ${ }^{1, *}$ Xuan Liu ${ }^{1}$ Yunyun Xia ${ }^{1}$ \\ ${ }^{1}$ School of Language and Literature, Harbin Institute of Technology, Weihai, Weihai, Shandong, China \\ *Corresponding author. Email:tougen@163.com
}

\begin{abstract}
Economic globalization and the internationalization of education are developing in depth. China has put forward the strategic guiding ideology for the internationalization of colleges and universities, and at the same time promotes multilingual foreign language education to a strategic development ideology. This article discusses the significance of multilingual education and the importance of cultivating international talents with multilingual ability in the context of the international development strategy of colleges and universities, and explores the teaching models and methods for students' multilingual ability training against the background of internationalization.
\end{abstract}

Keywords: Internationalization strategy of colleges and universities, Multilingual education, Multilingual ability training.

\section{INTRODUCTION}

China promotes multilingual foreign language education into strategic development thinking. Multilingual foreign language education should serve to enhance China's international competitiveness and serve the development strategy of China. Behind multilingualism is multicivilization. Foreign languages are not only tools, but also cultural carriers. The humanistic value of foreign languages is even more important. The value of language learning is not only the application value of actual communication, but is closely related to cultural exchanges, national security, political diplomacy, etc. Whether it is learning foreign culture or spreading Chinese culture, it is a must to rely on foreign language channels, so the society now needs more international talents with multilingual ability. During the implementation of "the Belt and Road Initiative", cooperation in multiple fields with countries along the route has increased the demand for multilingual international talents. In recent years, the internationalization of colleges and universities has continued to develop, and all colleges and universities are increasing their internationalization of running schools. There are more and more international exchanges and cooperation, and Chinese and foreign universities cooperate closely for common development. Language is a bridge of communication. When cooperating with colleges and universities in various countries, in addition to communicating in English, a large number of international talents who can speak multiple languages are needed to improve communication efficiency and promote cooperation. In the context of the internationalization strategy of colleges and universities, how to cultivate international talents with multilingual communication skills, comprehensive regional and country knowledge, broad international vision and the ability to participate in global governance is a question that colleges and universities should think about.

\section{INTERNATIONALIZATION DEVELOPMENT STRATEGY OF COLLEGES AND UNIVERSITIES}

With the development of globalization, colleges and universities in the world are rapidly moving from traditional international exchanges to the path of international development of colleges and 
universities. The "National Medium and Long-term Education Reform and Development Plan Outline (2010-2020)" clearly stated that higher education should "train a large number of international talents with an international perspective, familiar with international rules, and able to participate in international affairs and international competition." It also should "strengthen international understanding education, promote cross-cultural exchanges, and enhance students' knowledge and understanding of different countries and different cultures". [1] The international development of colleges and universities is not only the need to create a world-class university, but also the need to serve the national strategy, and it is an inevitable trend in the development of higher education. In recent years, many colleges and universities have implemented internationalization strategies, accelerated the process of internationalization of running schools, and developed and enriched the construction of internationalization. The goal of cultivating talents for international construction is not only to have a solid professional knowledge system, but also to have strong multilingual skills, cross-cultural communication competence, and deep humanistic quality.

For internationalization strategies, the terms commonly used in academic and educational circles include "education internationalization", "education globalization", "international education" and "intercultural education". The term in the documents of the Ministry of Education is "opening up of education to the outside world" or "opening to running schools". The connotation of the internationalization strategy is the process and phenomenon of the university's philosophy, elements and behaviors interacting across national borders. The characteristics of internationalization are openness, communication and versatility. [2]

Zheng Chunmiao, director of the International Cooperation Department of Southern University of Science and Technology, pointed out at the seminar on the internationalization capacity building of colleges and universities: the impact of the great changes in the world on Chinese colleges and universities is omni-directional. Colleges and universities need to adjust their global strategic layout and promote international connotative development based on their local conditions. Since January 2018, Tsinghua University has launched the "International Capability Enhancement Plan" (referred to as the "2020 Plan"). More than 70 faculties, departments, departments and units throughout the school work together to promote the continuous expansion and deepening of the school's internationalization capacity building. The "2020 Plan" integrates global competence into the whole process of student training. An international campus with multicultural and harmonious coexistence has been initially formed. Tsinghua University will continue to improve its internationalization capabilities, and enhance the school's international influence and international reputation.

\section{THE SIGNIFICANCE OF MULTILINGUAL EDUCATION IN THE CONTEXT OF INTERNATIONALIZATION STRATEGY OF COLLEGES AND UNIVERSITIES}

"Multilingual" refers to proficient in at least two or more second languages, excellent cross-cultural communication competence, or strong global understanding skills. The cultivation of multilingual ability in the context of internationalization, that is, the training of multilingual teaching and multilingual ability for non-English majors. Since the beginning of the 21 st century, the issue of the singularization of foreign languages in China has attracted the attention of scholars. In recent years, China has focused on how to change the current situation of the country's lack of languages and increase research on the training of multilingual talents. [3] Some scholars turned their attention to the United States, which is rich in foreign language resources and talents, and tried to get inspiration from it [4]. The American Council for Foreign Language Teaching and the Association of Foreign Language Teachers in various languages jointly formulated the famous "Foreign Language Learning Goals for the 21st Century", that is, the 5C goals of American Foreign Language Education [5], which requires foreign language learning to serve the existing multilingual and cultural communities in the United States and promote the development of multilingual teaching. American colleges and universities have formulated special regulations to promote foreign language learning, and strive to transmit classical excellent culture through foreign language education, cultivate students to tolerate and appreciate heterogeneous cultures and enhance international understanding, to meet the needs of the country, society and students' personal professional development [6].

Most of the foreign language education models in China's colleges and universities are that students 
only learn one foreign language, and they are not familiar with other foreign languages. This is not in line with the philosophy of international schooling. The schools should provide students with opportunities to learn different languages, promote multicultural education, cultivate students' ability to think about multiple cultures, and enhance international vision and global awareness. In the context of internationalization and in the development of internationalization, it is necessary to change the previous understanding, set up multilingual courses, and actively develop multilingual foreign language teaching in colleges and universities. A major obstacle to internationalization is language. To accelerate the process of internationalization, multilingual education is the only way to go.

Professor Ning Qi of Peking University proposed a public foreign language teaching reform aimed at fully opening up foreign language resources and cultivating multilingual international talents. [7] Cao Deming, President of Shanghai International Studies University, pointed out that today's world is entering a "multilingual+" era, and colleges and universities must actively reserve talents for the country's future needs and cultivate "multilingual+" international talents with strong ideological and political qualities, profound Chinese and foreign humanities, cross-cultural communication and outstanding professional capabilities. [8] Some scholars also proposed: "Foreign language education in China should focus on the scope and purpose of the language to promote the diversification of foreign languages." [9]

Under the concept of international schooling, colleges and universities and foreign colleges and universities have close exchanges and cooperation to carry out various forms of Sino-foreign cooperation in running schools. There are more international exchange programs, and talents with multilingual ability are more needed. In the process of internationalization, it can also provide a platform and opportunity for language exchange practice for multilingual education. By exploring the training model of multilingual international talents, it can provide better talent support for the internationalization of universities.

\section{IMPLEMENTATION IDEAS OF MULTILINGUAL EDUCATION AGAINST THE BACKGROUND OF INTERNATIONALIZATION STRATEGY OF COLLEGES AND UNIVERSITIES}

At present, the training of applied international multilingual college students in colleges and universities is still in its infancy. Colleges and universities have not yet cultivated multilingual international talents on a large scale. Only some foreign language universities offer such courses. Therefore, the talent training program for applied international multilingual college students is still being improved. Simply setting up a second language and a third language does not fully develop students' multilingual skills and enhance their international vision.

In the past, colleges and universities paid more attention to English education, but now students have generally improved their English scores when they enrolled. Some students have passed CET-4 when they enrolled, and many students can pass CET-6 through six months or one year of English learning. Therefore, students who have passed CET-6 can take German, French, Korean, Japanese and other minor languages instead of college English courses. [10] At the same time, students have a great demand for multilingual learning, such as animation, software and other majors want to learn Japanese, automotive majors have a lot of demand for German learning, and art majors are eager to learn Russian or French. Therefore, schools with multilingual teachers should offer multilingual teaching according to the needs of students. The specific implementation concept is as follows:

First, after enrolling students, the schools can conduct research according to their needs, offer multilingual courses and conduct multilingual teaching based on the research situation. They can allow students to choose the language according to their preferences after the audition. Relevant departments of the school and various colleges can jointly create a multilingual training model. They can also establish international education partnerships with colleges and universities in minority language countries, increase opportunities for international exchanges and internships, and send multilingual students to partner schools for exchange studies. 
Second, the training model can be tried in a variety of ways, such as:

- Majoring in English, offering German, Japanese, French and other multilingual courses as elective courses for students who are able to learn.

- Simultaneously offering English, German, Japanese, French and other multilingual courses. The hours and credits are the same, and the assessment methods are set according to the corresponding requirements for different languages.

- Making multilingual courses as publicly selected courses or general courses open to all majors of the school. In order to encourage students to take multilingual courses, corresponding course elective regulations can be promulgated, and the credit value of second foreign language courses can also be increased.

- Building a professional platform for multilingual subjects to provide students with a second degree in multilingual subjects.

- Setting up corresponding multilingual courses in the training plan for non-English majors.

- Opening courses related to language history, geography, culture and customs.

Third, in the limited teaching time, according to the needs of students, it is necessary to select textbooks reasonably, introduce high-quality MOOCs, and make full use of network means and resources to increase the opportunities for students to use the language. It is also a must to establish a special learning team for multilingual students, create 1-2 topics each year, and team members meet 2-3 times a month to carry out various activities such as expert lectures, oral corners, collective exchanges, and answer questions, which the people can communicate at any time through online means at ordinary times.

Forth, it will be of great significance to interactively cooperate with the school's department responsible for international education, create a practice base for multilingual learning, provide a language learning platform, and create a multilingual learning atmosphere. Language practice activities can be often held to show the effectiveness of students' learning. The schools can develop learning projects in various forms, and integrate theoretical teaching and practical teaching to improve the quality of talent training.
Fifth, the schools need to integrate internal and external resources to provide support for the establishment of multilingual courses and teacher training. They can also increase the number of languages and strengthen the construction of multilingual teachers. Teachers should be funded to carry out curriculum development and teaching research.

Sixth, it is necessary to determine the training goals of multilingual education:

- Students should have a solid basic knowledge of language and be proficient in various language skills;

- Students need to basically master the culture of multilingual countries and related humanistic and social knowledge;

- Students need to have a strong ability to use language for daily communication and written expression.

\section{CONCLUSION}

Language is a resource for cognition of the world and a way to absorb multiple cultures. Through exposure to different languages, students can be interested in language learning and improve their English learning ability. Multilingual ability can help students understand the latest economic, industry, and social frontier information in various countries and fields, so that students can choose the necessary skills for their own talents according to the needs of society. There is no need to test the level of multilingual learning, because the main purpose of multilingual education is to cultivate cross-lingual and cross-cultural talents, strengthen the teaching of languages from all over the world in Chinese colleges and universities, increase students' cognitive advantage of the world's multiculturalism, improve cross-cultural communication skills, and provide students with a personalized development path.

\section{AUTHORS' CONTRIBUTIONS}

Yan Teng is responsible for writing the manuscript, Xuan Liu contributed to revising, Yunyun Xia contributed to analyzing data.

\section{REFERENCES}

[1] Han Shuangmiao, World-Class Universities and Their Strategies for Internationalization: A Strategy Map Approach [J]. Fudan 
Education Forum, 2014(12): 10-16. (in Chinese)

[2] Sun Dong, Yu Le, Hu Wen, Talking About the Thinking and Implementation of the Internationalization Strategy of Colleges and Universities - Based on the Background of Electronic Information Colleges [J]. China After School Education, 2014(11). (in Chinese)

[3] Hu Wenzhong, Planning for foreign language education is imperative for China [J]. Foreign Language Teaching and Research, 2011 (1). (in Chinese)

[4] Wen Qiufang, Su Jing, The Theoretical Construction and Application of National Foreign Language Ability [J]. Foreign Languages in China, 2011(3). (in Chinese)

[5] Lu Xiaoyong, U.S. 5C Foreign Language Education in the 21st Century [J]. Foreign Language World, 2001(5). (in Chinese)

[6] Gong Xianjing, On the Rationales and Approaches Diversifying Foreign Languages Taught in American Universities since World War II [J]. Foreign Language Learning Theory and Practice, 2015(4). (in Chinese)

[7] Xiu Wei, Focusing on "Multilingual+" Talent Cultivation, and Exploring Development of Foreign Language and Literature Discipline [J]. Foreign Language World, 2019(6). (in Chinese)

[8] Cao Deming, An Analysis of the "Multilingual+" Initiative and the Methodology of Its Implementation [J]. Foreign Languages and Cultures, 2017(9). (in Chinese)

[9] Jiang Zhibin, Cultivating "Multilingual +" Foreign Language Talents: The Connotation, Path and Effect under the Background of AllCourse-Based Ideological and Political Education [J]. Technology Enhanced Foreign Language Education, 2020(4). (in Chinese)

[10] Feng Haiying, Reflections on the Reform of Second Foreign Language Education in Colleges and Universities under the Background of the Belt and Road [J]. Education Teaching Forum, 2021(4). (in Chinese) 